\title{
Social Capital Approach for Explaining Ethnic Conflicts Within a Liberal Society*
}

\author{
Michiya Kawamura \\ Osaka University, Osaka, Japan
}

\begin{abstract}
This paper examines the reasons why many ethnic movements surge in liberal societies - even though these societies are supposed to enable the coexistence of different types of people - and whether it is possible to resolve ethnic conflicts within these societies. Social capital, such as mutual trust, diffusion of information, and social support is used in this discussion, as successful coexistence in a liberal society is only possible when social capital is adequately provided to all people. Since social capital is generated from social networks, minorities want networks that may increase the likelihood that they will attain an adequate level of social capital. They attempt to build such networks by making their cultural symbols recognized by others. Confrontations that result from this kind of movement often cause ethnic conflicts. The key to resolution, then, is whether a broad network can be built, to which all different people are satisfactorily connected. As a result, this paper shows that even though such a resolution is theoretically possible, in reality there are three serious obstacles: (1) people tend to be driven by strong emotions; (2) people cannot accurately estimate the extent of suffering and/or the level of required support; and (3) minorities' primary networks are too solidified to be connected suitably to the wider network. These findings will contribute to the further argument of what conditions should be met in order to take feasible measures to resolve ethnic conflicts within a liberal society.
\end{abstract}

Keyword: ethnic conflict, multicultural coexistence, social capital, liberal society, social differentiation

\section{Introduction}

Modernization theory has noted that affective neutrality, universalism, and the achievement principle were becoming dominant in place of affection, particularism, and the ascription principle in modern society (Parsons, 1951, p. 67). In the same way, many scholars have insisted that people's attachment to their particular cultures and traditions would wither as time goes on (Park, 1950; Lipset \& Rokkan, 1967). Many liberalists asserted that even if some people maintain these attachments, modern society has advanced a framework that will enable them to live together. This framework is a liberal one in which people are free to pursue their own values, interests, and ethnic identities in their private life, while observing shared and generalized rules in the public sphere (Gordon, 1975, p. 88; Kymlicka, 1995, pp. 3-4).

The expectations of these theories came to be realized in the 1950s, yet ethnic conflicts have increased since the 1960s. Many conflicts have occurred even in developed regions where liberal order is firmly established, such as Occitania and Brittany in France, Catalonia and Basque in Spain, Scotland and Wales in Britain, Quebec in Canada and many others (Keating \& Loughlin, 2013). Developed countries have also been

\footnotetext{
* Acknowledgments: I would like to thank Editage (www.editage.jp) for English language editing. Michiya Kawamura, Associate Professor, Osaka School of International Public Policy, Osaka University.
} 
mired in disputes over the integration of immigrants, represented by many riots such as those in Paris in 2005 or in the UK in 2011. In the face of these problems, xenophobic politicians have gained momentum: Austria's Freedom Party joined the coalition government in 2000; Le Pen, the leader of the Front National (FN), reached the runoff election for the French presidency in 2002; and the populist governments of Hungary and Poland declared in 2015 that they will not take in any Syrian refugees. Why has the liberal expectation failed?

This paper will first address the theories of primordialism and instrumentalism, which have attempted to answer this question. Since both of them focus on the limited aspects of ethnic conflicts, their estimations of the possibility of ethnic conflicts cannot be considered reliable. A more balanced theory is needed in order to accurately explain how the impetus of ethnic movements surpasses the ability of liberal societies to make people coexist. Next, the ability of liberal frameworks to coordinate different interests and values are examined, and it is shown that this capacity is sufficiently exerted only when social capital (e.g., mutual trust, diffusion of information, and social support) is adequately distributed among people. Since social capital is generated from social networks, minorities want advantageous networks that may increase the likelihood that they will attain an adequate level of social capital. They attempt to build such networks by making their cultural symbols recognized by others. Confrontations that result from this kind of movement often cause ethnic conflicts. This paper posits that such an explanation of ethnic conflict may not be one-sided, and estimates the possibility of ethnic conflict resolution based on this explanation. As a result, it shows that even though such a resolution is theoretically possible, in reality there are three serious obstacles: (1) people tend to be driven by strong emotions; (2) people cannot accurately estimate the extent of suffering and/or the level of required support; and (3) minorities' primary networks are too solidified to be connected suitably to the wider network. These findings will contribute to the further argument of what conditions should be met in order to take feasible measures to resolve ethnic conflicts within a liberal society.

\section{Primordialism and Instrumentalism}

\section{Primordialism vs. Instrumentalism}

Primordialism and instrumentalism are the two major theories that have attempted to explain why the liberal expectation has failed (Cornell \& Hartman, 2007, p. 71).

Primordialism argues that people's fundamental values and cognitions are rooted in the particular culture in which they were born and raised. Since different cultures generate different worldviews, people from different cultures cannot fully understand each other. This is why people naturally have a primordial attachment to their own culture and feel hostility toward others. These emotions are so strenuous that a liberal framework cannot easily appease them. Even though different people appear to coexist peacefully in a liberal society, latent feelings of antagonism can be easily provoked; once such feelings are ignited, it is difficult to prevent them from escalating into severe conflict (Shils, 1957; Geertz, 1973; Isaacs, 1975; Grosby, 2005; Roshwald, 2006). This explanation appeals to those who are irritated with immigrants who seem unwilling to adapt to their host country, or those who are disgusted with radical secessionists such as the Irish Republican Army (IRA) in Northern Ireland or Euskadi Ta Askatasuna (ETA) in Basque. According to primordialism, confrontations stemming from cultural attachments are so strong and inevitable that it is virtually impossible to solve ethnic conflicts. ${ }^{1}$

\footnotetext{
${ }^{1}$ As a solution to this conflict, some multiculturalists suggest preferentially satisfying minorities' cultural attachment even beyond the liberal principle of equal treatment (Taylor, 1994; Raz 1994; Margalit \& Halbertal, 2004). This solution, however, tends to cause further hostility between the groups.
} 
Instrumentalism, in contrast, tries to explain modern ethnic conflicts from a socio-economic perspective. The boundaries between cultures are fluid and regularly change, diversify, or coalesce (Horowitz, 1985, p. 67). One's identity is not exclusively formed by a unique and fixed culture, but rather is subject to the influences of many changing and overlapping cultures. This malleability enables people to forge ethnic groups as a measure to pursue their own interests. When different interests confront with each other, ethnic conflicts arise. Instrumentalism includes two major sub-theories, both of which emphasize the instrumental role of ethnic symbols. Internal colonialism argues that majority groups try to use their cultural dominance to reinforce their economic exploitations of minority groups, while minority groups demand cultural equality to escape this doubly imposed disadvantage (Hechter, 1975; Hechter, 2000). Ethnic competition theory is a little different insisting that a cultural hierarchy is emphasized when the gap between majority and minority is shrinking. In such a situation, majority and minority actors compete for the same jobs and social status, and the majority tries to suppress the minority by emphasizing the latter's cultural inferiority (Nagel, 1995; Olzak, 1992; Olzak, 2006). An instrumentalist solution would be to resolve the underlying political or economic oppositions in order to prevent ethnic hostility from escalating into a serious conflict. Since people's cultural attachments are neither unique nor strenuous in nature, ethnic conflicts can be resolved if the problem of exploitation or exclusion is solved. ${ }^{2}$

\section{The Problems of Primordialism and Instrumentalism}

Primordialism and instrumentalism disagree over the cause of ethnic conflicts and possible resolutions, and neither can adequately explain why cultural attachments or economic or political interests can have such strong momentum that surpasses the ability of liberal frameworks to accommodate different people. Primordialists argue that people's cultural attachment is inherently stronger than this coordinating ability; however, the theory does not provide further explanation of this excessiveness. Instrumentalists also fail to address the question of whether claims for recognition can be confined to liberal frameworks and whether the underlying dispute over economic interests can be ultimately resolved in a liberal society. Considering that liberal systems are still widely accepted as legitimate, ethnic conflicts should be explained within the context of these frameworks' capacity. It is necessary to examine how strong this accommodating capacity actually is, and how the impetus of ethnic movements exceeds this capacity.

Moreover, both primordialism and instrumentalism are too one-sided to explain two ambivalent characteristics of ethnic conflicts. The first ambivalence is that both actors vying for cultural recognition and those pursuing political or economic interest are usually involved in the same ethnic movement (McKay, 1982; Scott, 1990; Eller \& Coughlan, 1993; Smith, 1998; Gil-White, 1999; Webb, 2013). Considering the Islamic revival in developed countries, Immigrants who were not initially very religious come to realize their need for Islam as a support system when they suffer from job discrimination, unemployment, and low academic achievement (Keaton, 2006). Simultaneously, others strengthened their religious beliefs in response to incompatibilities between Islamic and the Western values (Joppke, 2009, p. 10). Quebec nationalism shows similar ambivalence: Some Francophone Quebecois joined a movement aiming at overcoming the economic gap between Anglophones and Francophones, even though some Francophones take pride as a founding nation

\footnotetext{
2 Though post-colonialism can be roughly classified as a form of instrumentalism, it argues that ethnic conflicts can never be resolved because modernity inevitably creates mutually reinforcing economic and cultural hierarchies (Balibar \& Wallerstein, 1991; Hall, 1992).
} 
that is historically seen as having a "distinct society" (Handler, 1988). We cannot easily determine which motive is more profound; more importantly, we have to recognize that they are two equivalent motives underlying the same ethnic movements.

Thirdly, both interest- and emotion-oriented actors share an ambivalent attitude toward their culture. Even interest-oriented members do not use cultural symbols solely as tools (Bélanger \& Pinard, 1991). Rather, they sense some cultural affinity with other members before they get involved in that group, and this sense of affinity urges members to acknowledge their shared disadvantage and use the same symbols to pursue political or economic interests (Smith, 1998, p. 226). At the same time, though emotion-oriented members may appear to authentically desire recognition, their connection with the group is synthetically forged. The culture that appears during ethnic movements represents only selected aspects of the authentic culture that enable the members to feel instant emotional satisfaction. In sum, both interest- and emotion-oriented people have authentic commitment to their group that is nevertheless intentionally forged and maneuvered to some degree. Neither primordialism nor instrumentalism can fully explain this duality. ${ }^{3}$

If a theory focuses on limited aspects of ethnic movements, it cannot properly estimate how much impetus cultural movements have in exceeding liberal framework's ability to enable coexistence, because the estimation is subjected to the specific nature of those aspects. This is why neither primordialism nor instrumentalism can fully explain why liberal expectation has failed. In order to avoid this kind of distortion, we need a well-balanced understanding of ethnic movements that can properly address the two ambivalent characters of these movements.

\section{Social Differentiation and Social Capital}

\section{Social Differentiation}

This section examines how much capacity liberal frameworks actually have in enabling the peaceful coexistence of different kind of people. One of the most important principles for coexistence is that no one should suffer more persistent disadvantages than anyone else. While people always suffer something in the world, they can tolerate today's disadvantages only if society guarantees them equal opportunities to overcome their sufferings another day. This principle is crucial for the coexistence of different people (Choudhry, 2008, p. 17; Walzer, 1983, p. 19).

In order to avoid imposing persistent disadvantages on people, modern society has been divided into many spheres (e.g., politics, economics, education, and recognition). Social differentiation means that each of the spheres has its own particular role, primarily independent of the others (Walzer, 1983; Luhmann, 1995; Luhmann, 2013). The political sphere handles powers and collective decisions, the economic sphere deals with the distribution of income and economic growth, and the sphere of recognition concerns people's human dignity. The function of any one sphere cannot be carried out by another, the distribution of wealth should not be controlled by corrupt officials and democratic will-formation should not be distorted in favor of a few wealthy people. Since social differentiation eliminates the collusion of these spheres to some degree, people can obtain equal opportunities in life.

\footnotetext{
${ }^{3}$ Smith (1998) refers to this ambivalence from a primordialist view and Hechter (2000) from an instrumentalist perspective. However, both mainly call attention to the existence of the other aspect of culture, not fully explaining why this ambivalence can exist.
} 
However, in reality, the functions of each sphere are not altogether independent. For example, the role of education includes not only cultivating children's personalities but also providing knowledge and skills required for activities in the economic sphere. Thus, even those who come from poor backgrounds can move upward in society thanks to public education. The sphere of recognition also overlaps with the economic sphere in that a person whose cultural traits are positively evaluated can usually find a job without suffering ethnic or racial discrimination.

Ultimately, all of these spheres need to maintain positive inter-relationships in order to sufficiently guarantee people equal opportunities. However, the interaction between spheres requires complex coordination. School, for example, should equip children to flourish in adult society, yet it is often difficult to identify and teach relevant knowledge when the economy is rapidly evolving. As a result, education can sometimes widen disparity by producing adults who cannot adapt to the changing economic environment. ${ }^{4}$ The sphere of recognition serves as another example. Its major function is the universal protection of human dignity, and this ideal should not be distorted by the concern for economic efficiency or political stability. However, to realize this ideal, it is necessary to guarantee some basic resources such as income, status, social connections, and reputation, because these are considered integral to modern human dignity (Sen, 1992, p. 116). Since these resources are provided from other spheres, disadvantaged people will emerge unless these provisions across boundaries are sufficiently and equally executed. To conclude, the separation of social spheres requires inter-sphere corroborations in order to secure equal opportunities for people; however, these corroborations are not always appropriately established, because it is difficult to specify the proper conformation of corroborations.

\section{Necessity of Social Capital in a Differentiated Society}

To offset the insufficient corroborations among the spheres and avoid the resulting exclusion, all people should be provided with social capital such as trust, access to information, and social cooperation (Ostrom, 1990; Putnam, 1993; Banerjee \& Duflo, 2011). Social capital is defined as resources that people can mobilize in social networks to gain various profits such as wealth, power, reputation, well-being and so on (Lin, 2008, pp. 51-52). Social capital and social networks, however, are not synonymous. Social networks are interpersonal relationships in which people frequently contact with each other. These networks serve as the base on which social capital is generated and utilized, but they themselves will not bring about profits as social capital does (Lin, 2008, p. 58). Social capital usually functions in unofficial situations, for example, even if people are not taught relevant knowledge and skills, they can maintain a certain standard of living by acquiring that knowledge through exchanging information with others, or by training those skills through social interactions in families, communities and other networks. Similarly, even though people may lack the necessary income or social status to be regarded as respectable persons, they can preserve their human dignity by promoting mutual trust or making themselves understood through information exchange with others.

As these examples show, if people have sufficient social capital, they can make up for a lack of various resources caused by the insufficient corroboration between the spheres. By utilizing social capital, people can obtain basic resources such as knowledge, skills, political influence, and reputation, which are necessary for enjoying equal opportunities. This can even be applied to members within a closed traditional group such as

\footnotetext{
${ }^{4}$ Bourdieu and Passeron (1977) explained how the principal function of education tends to be the preservation of symbolic hierarchy in which upper-class culture enjoys the privilege. This hierarchy is maintained relatively independent of the necessity to provide practical education.
} 
conservative Muslim immigrants or aboriginal people hostile to the majority's culture. Liberal society, in principle, guarantees the existence of closed traditional groups based on the freedom of association (Kukathas, 2003). Nevertheless, a closed group may still find it difficult to access important resources such as adequate income or recognition by other people. In gaining income, members may fear that they are compelled to abide by the majority's conventional way of business. However, if the spheres of economy and recognition are discrete, members can search for alternative business options that would not compel them to culturally assimilate. They can pursue this objective further by utilizing their social capital, finding a less assimilative workplace through information exchange or building a new business in cooperation with other minorities. In the case of pursuing cultural recognition, members may be less content because they can never gain full recognition of their culture but rather only the freedom to pursue it. However, this level of recognition may be satisfactory if they can maximize the recognition by using their social capital, building mutual trust with other group members and providing others with more information about their culture. In this way, even a closed isolationist group has somewhat positive incentive to participate in a well-differentiated society as far as it can expect to obtain sufficient social capital. ${ }^{5}$

To conclude, the ability of liberal frameworks to enable the peaceful coexistence of different people has a specific limitation: It can be exercised only when the corroborations among social spheres are well-established, or when social capital is adequately provided to offset insufficiency within these corroborations. Therefore, majorities should not criticize minorities as being selfish or irrational just because they cannot adapt to the present liberal framework. This problem may be caused by the deficiency of corroborations or the lack of social capital. Conversely, if these conditions are met, even a closed traditional group can coexist with others in a liberal framework. From this perspective, it can be assumed that when liberal expectations prevailed in the 1950s, people were content with the development of social differentiation without noticing the underlying improvements of the corroborations or the increase of social capital. However, as the corroboration between spheres or distribution of social capital was not always successful, people began to question the accommodating ability of liberal frameworks since the 1960s.

\section{Ethnic Movements as Pursuits for Social Capital}

\section{Two Types of Movement that Address the Problem of Liberal Societies}

A differentiated society gives rise to inequality amongst people whenever it fails to maintain good corroboration between spheres or to provide sufficient social capital to offset the inadequate corroboration. To overcome this inequality, there are two options.

The first is to make the corroboration of social spheres more sophisticated. For example, schools should coordinate their curricula with the changing economic environment, or the government should identify the basic resources that people require to be good citizens, and provide them. These institutional measures may not be perfectly implemented and people may have to utilize their social capital to offset this deficiency. However, social capital, including mutual trust, has such an amorphous nature that the effect of its utilization may be unstable. Therefore, it is important to continue the sophistication of social institutions in order to depend less upon people's utilization of social capital. Indeed, many social movements can be conceived as activities to

\footnotetext{
${ }^{5}$ Kymlicka (2001, p. 169) similarly argues that "immigrants accept the principle of integration into common institutions; they are simply seeking fairer terms of integration". Yet Kymlicka does not necessarily conceptualize the fair terms of integration as an adequate provision of social capital to everyone.
} 
claim for this sophistication. Consider a labor movement that demands the safety of workplace, occupational education, and the right of collective action, or a civic movement that calls for the protection of freedom of expression, the right to live in peace, and the protection of the natural environment. If a claim for recognition of one's culture is specified enough to be treated as a matter of human rights, this problem is rationally addressed through a civic movement.

One weakness within this institutionalization approach is that we cannot identify all the causes of any given problem. When people cannot appropriately adapt to the shifting economic environment, it cannot be said unequivocally that this is due to their lack of suitable knowledge and skills; it may also be related to fierce job competition, a crumbling social security system, bad educational environment, or any number of unspecified factors. Similarly, if people suffer from insufficient recognition, it may not only be due to their poverty but also to their fewer social connections, the result of inadequate human rights education, or still other reasons that cannot be clearly identified. Accordingly, the sophistication of social systems is only a partial solution, as it can only address the disadvantages of a limited number of people whose reasons for suffering are easily identified. For those who fear being left behind by this sophistication, the provision of social capital is important. ${ }^{6}$ They can try to correct their problems by utilizing their social capital, such as through exchanging information on how to overcome their suffering, assisting each other to offset shared disadvantages, and appealing together the shortcomings of the current systems. Therefore, social movements in liberal society are not always rational ones with defined targets such as labor or civic movements. There also are seemingly irrational movements that pursue the amorphous and unmanageable resource of social capital.

\section{Utilizing Cultural Symbols to Gain Social Capital}

Most movements pursuing social capital take the form of ethnic movements because cultural symbols are useful in obtaining this capital. An ethnic movement can thus be understood as a call for the fair distribution of social capital by appealing for the recognition of certain cultural symbols. The following explains how people use cultural symbols to gain social capital.

As many theorists have stated, social capital such as mutual trust, access to information, and availability of social support arises from people's continuous contacts (Coleman, 1990; Lin, 2008). It follows that people can easily obtain social capital within a primary group or network such as family, workplace, neighborhood (Cooley, 1909). Primary networks may look similar to cultural groups, yet these networks are defined in terms of the frequency of social contacts rather than cultural similarity or shared heritage. People in these networks do not necessarily have a sense of belongingness, but are aware of the high frequency of their contacts. Social capital obtained in these small networks may not be entirely helpful in modern society. To gain a job, for example, workers need to be trusted by the employer who has not known them before, and should be able to collect adequate information on job applications from unfamiliar persons (Granovetter, 1974). To be a good citizen, people should be exposed to a wide range of information on how to behave appropriately in political, economic, and social spheres (Nussbaum, 2000, p. 78). Since this generalized social capital arises from wider social contacts or interactions, people who want this capital need to connect their small networks more substantially with the greater network. ${ }^{7}$

\footnotetext{
${ }^{6}$ This is not true of minorities only. When social systems begin to change, majorities also uneasily think that their social capital that has sustained them so far becomes less influential.

7 We can also conceive of Kymlicka's societal culture as a network that provides its members with social capital. However, Kymlicka focuses more on whose societal network can legitimately provide social capital than on how the network should be built.
} 
Often, however, the unique characteristics that local networks automatically take on prevent them from connecting to the wider network. In terms of peaceful coexistence, the most recommendable way to overcome this problem is the process of "get(ting) used to one another" (Appiah, 2006, p. 78). Through the accumulation of conversations, transactions, and interactions, people from different primary networks can acclimate to each other and facilitate smoother connections unhindered by fear and hostility. As habituation means mere "engagement with the experience and the ideas of others" (Appiah, 2006: 85), it can serve to connect many different networks without forcing people to share any rigid relationship. Conversely, as cultural homogeneity or deep mutual understanding requires a compelling measure to make a wide range of people share it, it is unlikely to build smooth connections of different primary networks.

Those who suffer a serious lack of social capital, however, often cannot endure the lengthy process of habituation. They want to obtain social capital quickly. This is where cultural symbols are helpful, as symbols represent people's primary network so that others can easily conceptualize it. This function of symbols enables people to build the broader connection more quickly. If these symbols are successfully recognized and their values are readily accepted in a broader context, people can connect their primary networks to the wider network so advantageously that they can obtain a substantial amount of social capital through this broader network. Cultural majority usually succeeds in this task, and minorities try to achieve this to overcome their disadvantages. In this way, pursuits for social capital turn into struggles for cultural recognition ${ }^{8}$. As the utilization of cultural symbols deviates from connection-building through habituation, some people might fear that ethnic conflicts will naturally become serious. However, the severity of ethnic conflicts ultimately depends on the extent of this deviation. If people's symbols are recognized as smoothly as habituation, any ethnic conflicts are not likely to be serious. ${ }^{9}$

\section{Explaining Two Types of Ambivalence}

Thus far, the cause of ethnic conflicts has been explained by focusing on the inadequate distribution of social capital and the mechanism of generating social capital through social networks. Based on this argument, this paper will examine whether it is possible to resolve ethnic conflicts. Prior to this examination, the argument will first be confirmed as reliable. Though primordialism and instrumentalism also estimate the possibility of conflict resolution, their conclusions are not reliable because both theories focus on the limited aspects of the conflict. In order to avoid this limitation, the argument must address two types of ambivalence inherent in ethnic movements that both primordialism and instrumentalism have so far left unexplained.

\section{Different Motives in the Same Movement}

The first type of ambivalence is that those who seek cultural recognition and those who pursue political or economic interests are involved in the same ethnic movement. In the sphere of recognition, people tend to react with fear or hostility to unfamiliar persons. Through mutual trust or shared knowledge, however, people can live together despite even significant cultural differences as in Switzerland (Kriesi \& Trechsel, 2008). It is the lack of trust or knowledge that leads to conflict even when cultural differences are relatively minor-as with Croatians and Serbs (Ignatieff, 1999). Thus, the severity of conflict is not determined by the extent of cultural

\footnotetext{
${ }^{8}$ In modern society, laws and rules are so reflexive that they are repeatedly checked and revised in terms of logical and normative consistency (Luhmann, 1972). Therefore, it is relatively easy for people to protest that the rules that do not respect their cultural symbol are illegitimate.

${ }^{9}$ German or Scandinavian immigrants in the United States are applied to this case (Gordon, 1964, p. 133).
} 
difference alone, but by the ratio between the extent of cultural difference and the amount of social capital. Nevertheless, it is true that emotional attachment to one's culture can trigger an ethnic conflict, and in this respect, the theory of primordialism has validity.

However, as instrumentalism points out, confrontation of economic interests can also develop into an ethnic conflict. Poor people or cultural minorities, for example, are likely to have their ability and personality underestimated by majority, resulting in obvious disadvantages in job competition or lower wages. Since elements of social capital such as trust can ameliorate these sufferings, disadvantaged people appeal for the recognition of their cultural symbols in order to foster trust and understanding. In this respect, instrumentalism is also valuable.

Taking these two cases into consideration, it can be concluded that grievances regarding the lack of social capital can concurrently arise from different social spheres. Thus, neither primordialism nor instrumentalism is sufficient in that each assumes a single cause of ethnic conflict. A new theory should consider that the true cause of ethnic conflict is people's discontent over a lack of social capital, while primordial attachment and the pursuit of interests merely serve as triggers to the conflict. However, an important question remains: Why do people with different grievances join the same ethnic movement, rather than make separate ones?

In general, people want to be equipped with sufficient social capital to be able to deal with any unexpected disadvantages. They are wary of being left behind by insufficient sophistication of social systems that could relieve a limited number of people whose disadvantages are easily identified. This is why people launch ethnic movements in pursuit of social capital, rather than labor or civic movements that demand specific corrections of the social system. When people suffer from disadvantages in one social sphere, they are often afraid that the social capital they lack may also be necessary to function in other spheres. For example, if someone's ability and skills are underestimated in the labor market, they worry that the lack of trust and information that caused this underestimation will also give rise to misrecognition of their identity in another sphere. The reverse is true as well: if people are misunderstood by others who do not know them well, this insufficient circulation of information may prevent them from finding a job or conducting a business transaction. Thus, both parties who are grieved-one in the sphere of economics and the other in the sphere of recognition-share the same kind of anxiety. To try to overcome it, they become involved in the same ethnic movement.

Of course, their feelings and objectives may not be perfectly in parallel. For example, among Muslim immigrants in Europe, those who are disgruntled about income and educational gaps and those who are angry with people's prejudices against Islam may differ with respect to membership of the group, the type of social capital they pursue, or the degree of eagerness with which they are involved (Bowen, 2004). However, some fusion and interchange of attitudes are often observed, for example, in Yugoslavia, the conflict that led to the dissolution of the country was initiated by a confrontation of its republics over administrative power, but fierce ethnic sentiments grew predominantly thereafter (Bennett, 1995). Conversely, in Northern Ireland, after serious struggles with explosive ethnic passions, there arose the possibility of compromise regarding the distribution of power and wealth (Cox, Guelke, \& Stephen, 2006). In sum, people who bear grievances in different social spheres can come to have the same aims with respect to social capital, and this is why different motives of demanding recognition and pursuit of economic interest coalesce in the same ethnic movement.

\section{Culture Affecting People as Well as Maneuvered by People}

The second type of ambivalence is that the cultures in ethnic movements have two seemingly incompatible properties: one that forces its members to think and behave in a certain way and the other that is forged and 
maneuvered by its members. This type of ambivalence concerns the process of pursuing social capital, while the first type of ambivalence refers to the motives for requiring social capital. Attachments to cultural symbols that appear in the pursuit of social capital should be distinguished from the primordial attachment. Primordial attachment is just one of many triggers to an ethnic conflict, and not all people involved in the movement pursue its fulfillment. In contrast, everyone must satisfy the attachment to his or her cultural symbols because this fulfillment is necessary for obtaining social capital. If social capital is obtained, any desire including primordial attachments will be fulfilled through the utilization of this capital. Thus, what is crucial for resolving ethnic conflicts is attachment to cultural symbols, not primordial attachment.

The broader networks through which people obtain generalized social capital have some authentic aspects. To be able to guarantee people sufficient generalized social capital, the wider networks should appropriately include primary networks within them. Since people inherently have some attachments to the pre-existing primary networks in which they are situated, the well-established broader networks must properly accept these attachments. People represent this primary network with cultural symbols and demand recognition of these symbols in building the wider network. If others suspect that this claim for recognition is disguised only to pursue economic interests, the broader network built on this perceived insincerity can generate neither sufficient mutual trust nor smooth circulation of information. In order to gain adequate social capital, people must have others accept their attachment as sincere. However, it is important to note that these attachments may be weaker than primordialists suppose because the primary network is a network, not an entity, and that others' acceptance of these attachments should not be necessarily based on deep mutual understanding, but rather on habituation.

Ethnic movements also have invented and maneuvered aspects. For example, whether Native Americans identify themselves as members of small subgroups like Navajo or Pueblo, of the Native American group as a whole, or simply as American residents depends on factors such as political events (e.g., the civil rights movement in the 1960s), their area of residence (e.g., reservation or city), and the frequency of mixed marriages (Cornell, 1990; Nagel, 1995). In addition, cultural identity is not always chosen by the people; sometimes, it is forced upon them. For example, Cape Verdeans immigrants in America originally identified themselves as Portuguese based on their shared language with immigrants from Portugal, yet Americans regarded them as blacks because of the preeminent significance of race in American culture. In the end, second-generation Cape Verdeans began to think of themselves as "blacks" (Cornell \& Hartmann, 2007, p. 194). People in this position tend to calculate which unit they should choose as their representative ethnic group in order to gain the social capital effectively. If Cape Verdeans choose black as their ethnic group, they can expect a massive mobilization under this banner. The upshot is a significant boost in momentum, yet the aims of the movement may be so diversified that Cape Verdeans end up unsatisfied even if the movement is successful. Conversely, if they adopt Cape Verdean as their identity, they may feel better suited within that construct, but their relatively small movement is likely to be ignored.

Though these maneuvers and calculations are found in almost all ethnic movements, people concurrently have a sincere attachment to any unit they choose and seek to have this attachment accepted by others to gain social capital ${ }^{10}$. In the end, the ambivalence of the culture-it constitutes people's affections as well as is

\footnotetext{
${ }^{10}$ Sen (2007) similarly argues that people have different identities each of which is constituted by groups or social contexts, and that people can rationally choose a suitable identity in a given situation. His argument is normative in emphasizing the power of reason that enables people to avoid the violent clash between different identities. He does not refer, however, to the fact that people often calculate which identity should be chosen solely on the basis of effectively gaining social capital.
} 
maneuvered by people-comes from the nature of social capital, which is ultimately a resource but at the same time arises from social ties.

\section{Three Factors that Make Conflicts Intractable}

It may be safe to say that this new argument avoids the one-sided limitations of primordialism and instrumentalism, because it explains the two ambivalent characteristics of ethnic movements. Then, this paper will address the question of whether ethnic conflict is tractable or intractable in nature.

First, ethnic conflicts will continue to arise in the future. As described in Section 3, the distribution of social capital is always problematic in liberal societies. A liberal society is differentiated into many spheres, and corroborations between the spheres are changing because it is almost impossible to identify the ideal formation of these corroborations. As a result, the pursuit of social capital will never end because people need this capital to offset the insufficiency of these changing corroborations. This is evident in the shift from an era of heavy industry to one of service, or from a society in which foreigners' rights expand to one in which border controls are strengthened. As societal compositions shift, people need new abilities and resources to maintain their standard of life and mental balance. ${ }^{11}$ In any society, there are always people who cannot acquire these abilities or resources and must seek more information or social supports to offset these shortages. Thus, distributional of social capital is a persistent problem, and ethnic conflicts will continue to arise.

One example of this is the Quebec national movement: the old nationalism rooted in the Catholic-dominant rural society had once calmed down in the 1950s, yet more or less different type of nationalism appeared in the 1960s following Quebec's rapid industrialization called the Quiet Revolution (Handler, 1988). Similarly, the circumstances of disadvantaged African-Americans began to improve after the civil rights movement in the 1960s, but their situation worsened again when the industrial structure changed into a more globalized and finance-oriented economy, because the laws and unions that had protected many of these workers in manufacturing factories were no longer as relevant (Wilson, 1999; Wilson, 2012).

Nevertheless, the phenomenon of social conflict might decrease if individual ethnic conflicts are resolved every time they arise. Therefore, the ultimate solution is to rebuild a wide network that encompasses both minorities and majorities, to provide minorities with social capital through this network, and to enable the minorities to fulfill their emotional attachments or economic interests with this social capital. Though this solution looks relatively straightforward, it is quite difficult to implement in the real world for the three following reasons.

\section{Excessive Emotions}

First, people involved in an ethnic movement tend to be driven by strong emotions. Referring to the basic structure shown in Section 4, the people in a movement have only to appeal to a milder cultural attachment than a primordial one to build a wider network and gain social capital. Once they gain this capital, they can satisfy their emotional or distributional demands based on their own efforts; therefore, they will no longer appeal to the strong emotions to obtain further resources. However, minorities with a severe deficit of social capital are often overly hasty in their efforts to have others recognize their primary network. In such cases, they are not willing

\footnotetext{
11 In order to enjoy a certain quality of life, all people should have their basic capabilities protected. Nussbaum (2000, p. 78-80) lists 10 basic capabilities to be protected in any society and era, including life, bodily health, emotions, and practical reason. Yet Fabre and Miller (2003) insist that as actual societies are extremely different from each other, Nussbaum's universalization is impossible.
} 
to wait a long time for others to habituate to their primary network but rather adopt more salient cultural symbols in order to accelerate recognition of their culture. Once these hasty measures are accepted in society and appeals to ethnic sentiments are popularly conducted, it becomes difficult to control people's impatience. Minorities are often too impatient to be satisfied with a mere acquisition of social capital, but demand direct redistribution of economic resources or immediate recognition of their culture. Moreover, minorities tend to get so enthusiastic that their claim for recognition becomes the highest goal to which the aim of gaining social capital is subject. Thus, minorities are likely to assume that all of their shortages of income, job, political influence, and other resources are a direct consequence of their lack of recognition. Even if some of these disadvantages are improved or overcome, they will still complain that they have not been recognized because some of their claims remain unsatisfied. By unifying their complaints, minorities strengthen their grievances and become unwilling to dissolve this unified discontent into individual demands that can be dealt with separately. This escalation was evident in Rwanda where the conflict began with a class struggle between Hutu and Tutsi (Lemarchand, 2004), or in Yugoslavia where the struggle was initiated by a dispute over the distribution of power in the federation (Bennett, 1995; Silber \& Little, 1997).

There are other ethnic movements, however, in which less sensational attitudes are dominant. In Occitania, for example, the regional movement had been composed of three major factors: school teachers calling for the defense of decaying Occitan language and culture, vineyard farmers and miners demanding regional economic development policies, and nationalists seeking independence (Touraine et al., 1981, pp. 286-287). There was no intrinsic principle unifying these three factors in the movement, yet people's vague but pressing anxiety for the collective death had narrowly sustained the movement (Touraine et al., 1981, pp. 287-288). The movement, in actuality, was highly decentralized and had consistently been on the verge of collapse. However, local governments in Occitania eventually acquired autonomous rights for vocational training and educational systems from the central government in the 1980s (Keating, 1998, p. 64). Though its grievances are not completely resolved, Occitania won political support for its economic development and cultural preservation because the decentralized tendency of the movement happened to prevent their demands from becoming emotionally overdriven.

\section{Ambiguous Concepts of Social Capital and Social Network}

Even if people avoid the escalation of ethnic sentiments, conflicts will not always be resolved. This could be due to the second problem: the difficulty of identifying the extent to which minorities are disadvantaged and how much initial support is needed to connect their primary network to a wider network. These questions are imperative in solving ethnic conflicts, but the concepts of social capital and social networks are so ambiguous that it is difficult to answer accurately to these questions.

Owing to the abstract nature of social capital, people can arbitrarily estimate how much they suffer from the lack of these resources. For example, majorities are often afraid that the social context that stabilized their conduct, expectations, and values will be broken by a heavy influx of immigrants; yet, it is difficult to accurately estimate how much negative effect they actually suffer as a result of immigration. Majorities, then, tend to overreact, often trying to exclude or marginalize immigrants as a protection measure. However, minorities are not entirely innocent, either. As post-colonialists point out, minorities truly suffer from many unnoticeable exclusions under the fair and neutral guise of modern society (Balibar \& Wallerstein, 1991; Hall, 1992). Many of these hidden exclusions are caused by their lack of social capital, yet social capital, such as 
mutual trust or access to information, supports human lives so tacitly that it is difficult to estimate how severely minorities suffer from the lack of this capital. To correct these exclusions, society does need to provide minorities with more resources than had been previously expected. However, minorities may take advantage of this difficulty of estimation to demand far more resources than they really need to correct their disadvantage.

Building a wider network is also difficult due to this type of exaggeration by both parties. Minorities usually feel it is difficult to connect their primary network to a wider one because they believe the image of their primary network is feared or despised by others. When this is the case, some initial support may be necessary to nudge smaller primary networks into the wider one, yet the extent of this support is also ambiguous and potentially controversial. Minorities are likely to demand greater support and better distribution regardless of actual need; conversely, majorities tend to think that such a network will not naturally and smoothly facilitate mutual trust, information exchange, and voluntary cooperation, but rather mandatorily redistribute social and economic resources. Even if all parties agree to prioritize network-building over instant recognition or redistribution, they tend to dispute over how the initial support should be implemented.

\section{Solidification of Primary Networks}

The third problem is the shape of the primary network itself. Because they feel marginalized and need a strong mutual support system, minorities often build a closed primary network that cannot easily connect to a wide range of people outside their group. ${ }^{12}$ In order to mitigate their feelings of alienation, they try to maintain distinct conventions and traditions that confirm their emotional ties (Smith, 1991, p. 162). They may also forge tight bonds to assist each other in finding jobs, starting businesses, and obtaining information and resources (Wilson \& Portes, 1980, p. 315). Furthermore, they need consolidated bodies that can collectively call for immediate recognition of their culture or direct redistribution of economic resources (Nielsen, 1985, p. 136). However, the underlying reason for their disadvantage is their lack of universal social capital. If actors in the primary network are too focused on forging internal solidarity to connect outward, they cannot gain the generalized social capital that could have been obtained if their focus was on connecting their primary network to the larger one. These phenomena are typically illustrated in enclaved Hispanic groups in the United States. Scholars point out that these enclaves create strong in-group loyalty, organize a variety of enterprises, and concentrate in a distinct spatial location in which few are fluent in the language of their host society (Portes, 1981, p. 291). Cuban immigrants in Miami are often cited as a successful example of this, yet many ethnic enclaves have not flourished as well as this one (Sanders \& Nee, 1987). Many people in these enclaves have difficulty in integrating into the wider society and remain marginalized in low-income areas, having poor English ability and high dropout rates from school (Cutler, Glaeser \& Vigdor, 2008). Though consolidated primary networks may have fostered a social capital that is particular to their group, this level of capital will not alleviate their disadvantages within the wider society. Nevertheless, people are likely to prefer solidified primary networks because the benefits associated with this solidification are immediate in nature.

\footnotetext{
${ }^{12}$ This closed primary network may correspond to Putnam's concept of bonding social capital, where he makes a distinction between bonding and bridging social capital: bonding capital is "inward looking and tend(s) to reinforce exclusive identities", having an advantage in "undergirding specific reciprocity and mobilizing solidarity", whereas bridging capital is "outward looking and encompass(es) people across diverse social cleavages", serving to make a linkage to external assets and to diffuse information (Putnam, 2000, p. 22).
} 


\section{Conclusion}

In examining the underlying structure of ethnic conflict, it is important to remember the following four concepts. Firstly, liberal societies' capacity to enable the coexistence of different types of people is conditional; it can do so only when social spheres such as politics, economy, and recognition build appropriate corroborations with each other, or when people are adequately and equally provided with social capital that serves to offset the insufficiency of these corroborations. Secondly, when social capital is insufficiently provided to people, ethnic conflicts arise. Though the claim for recognition or the pursuit of economic interests seems a plausible cause of ethnic conflicts, they are more likely the triggers and the dispute over social capital is actually the deeper, underlying impetus. Thirdly, though this kind of disputes continuously arise in liberal societies, ethnic conflicts could be resolved in principle if people build better and wider networks to which many primary networks are inclusively connected. From these wider networks, people can obtain an adequate amount of generalized social capital. The least coercive way of making these connections is for people to habituate to the unique traits of others' primary networks. Fourthly, if cultural symbols are utilized to build broader networks, the resolution of conflicts is likely to be difficult, because there are three obstacles that hinder the construction of better and wider networks: (1) people tend to be driven by strong emotions; (2) people cannot correctly estimate the extent of their suffering and how much support they need; and (3) minorities solidify their primary networks to the extent that they cannot smoothly connect to the wider network.

Based on these findings, two measures to mitigate ethnic conflicts are recommended. Firstly, the corroborations of social spheres must become more sophisticated in order to depend less on social capital. This, in itself, is not a sufficient solution, because even if redistribution schemes based on one's income are developed or a ban on discrimination is universally implemented, some ethnic minorities may still suffer from unemployment or lack of recognition. This is why ethnic conflicts would not ultimately end within liberal societies. However, these sophistications can serve to mitigate minorities' suffering and help to clarify what kind of disadvantages they still suffer and how much social capital is needed to overcome their sufferings. In order to resolve ethnic conflicts, it is important to align with rational movements that seek the sophistication of social systems, such as civic movements or labor movements.

Secondly, place an arbitrator between the two confronting ethnic groups. The three difficulties of conflict resolution come from people's myopia: people hurry to build a favorable connection of networks, incautiously determine how much social capital they lack or how much support they need to build a wider network, and quickly try to offset their lack of social capital with their solidified primary networks. Implementing an arbitrator can serve to overcome this myopia. Since the distance between the arbitrator and each opponent is closer than the direct distance between both opponents, the arbitrator may be able to urge both parties to more objectively estimate the difference in their situations and to more smoothly build a network via the arbitrator. For example, modernized Muslims might be seen as arbitrators who exercise these functions by standing between secular nationals and traditional Muslim immigrants. However, the difficulty of finding suitable arbitrators remains a problem.

As these two recommendations are not fully elaborated in this paper, further clarification of these measures is needed for future development. This effort will contribute to the reasonable resolution of ethnic conflicts and this paper seeks to provide an analysis of the underlying structure of ethnic conflicts that could serve as a solid basis for this effort. 


\section{References}

Appiah, K. A. (2006). Cosmopolitanism: Ethics in a world of strangers. Penguin Books.

Balibar, E., \& Wallerstein, I. (1991). Race, nation, class: Ambiguous identities. (C. Turner, Trans.). London: Verso.

Banerjee, A., \& Duflo, E. (2011). Poor economics: A radical rethinking of the way to fight global poverty. New York, NY: Public Affairs.

Bélanger, S., \& Pinard, M. (1991). Ethnic movements and the competition model: Some missing links. American Sociological Review, 56(4), 446-457.

Bennett, C. (1995). Yugoslavia's bloody collapse: Causes, course and consequences. New York, NY: New York University Press.

Bourdieu, P., \& Passeron, J. C. (1977). Reproduction in education, society and culture. (R. Nice, Trans.). Publisher: London \& Beverly.

Bowen, J. (2004). Does French Islam have borders? Dilemmas of domestication in a global religious field. American Anthropologist, 106(1), 43-55.

Choudhry, S. (2008). Bridging comparative politics and comparative constitutional law: Constitutional design in divided society. In S. Choudhry (Ed.), Constitutional design for divided societies: Integration or accommodation (pp. 3-40)? New York: Oxford University Press.

Coleman, J. S. (1990). Foundations of social theory. Cambridge: Harvard University Press.

Cooley, C. H. (1909). Social organization. New York, NY: Scribner.

Cornell, S. (1990). Land, labor, and group formation: Blacks and Indians in the United State. Ethnic and Racial Studies, 13(3), 368-388.

Cornell, S., \& Hartman, D. (2007). Ethnicity and race: Making identities in a changing world (2nd ed.). Thousand Oaks, CA: Pine Forge Press.

Cox, M., Guelke, A., \& Stephen, F. (Eds.) (2006). A farewell to arms? Beyond the Good Friday agreement. Manchester University Press.

Cutler, D. M., Glaeser, E. L., \& Vigdor, J. L. (2008). When are ghettos bad? Lessons from immigrant segregation in the United State. Journal of Urban Economics, 63(3), 759-774.

Eller, J. D., \& Coughlan, R. M. (1993). The poverty of primordialism: The demystification of ethnic attachments. Ethnic and Racial Studies, 16(2), 183-202.

Fabre, C., \& Miller, D. (2003). Justice and culture: Rawls, Sen, Nussbaum and O’Neil. Political Studies Review, 1, 4-17.

Geertz, C. (1973). The interpretation of cultures: Selected essays. New York, NY: Basic Books.

Gil-White, F. (1999). How thick is blood? The plot thickens... If ethnic actors are primordialists, what remains of the circumstantialist/primordialist controversy? Ethnic and Racial Studies, 22(5), 789-820.

Gordon, M. M. (1964). Assimilation in American life: The role of race, religion, and national origins. New York, NY: Oxford University Press.

Gordon, M. M. (1975). Theory of racial and ethnic group relations. In N. Glazer, \& D. P. Moynihan (Eds.), Ethnicity: Theory and experience (pp. 84-110). Cambridge, MA: Harvard University Press.

Granovetter, M. (1974). Getting a job: A study of contacts and careers. Chicago, IL: The University of Chicago Press.

Grosby, S. (2005). Nationalism: A very short introduction. Oxford: Oxford University Press.

Hall, S. (1992). The question of cultural identity. In T. McGrew, S. Hall, \& D. Held (Eds.), Modernity and its future (pp. 274-316). London: Polity Press.

Handler, R. (1988). Nationalism and the politics of culture in Quebec. Madison, WI: University of Wisconsin Press.

Hechter, M. (1975). Internal colonialism: The celtic fringe in British national development. Publisher: University of California Press.

Hechter, M. (2000). Containing nationalism. Oxford: Oxford University Press.

Horowitz, D. (1985). Ethnic groups in conflict. Publisher: The University of California Press.

Ignatieff, M. (1999). Nationalism and the narcissism of minor differences. In R. Beiner (Ed.), Theorizing nationalism (pp. 91-102). Albany, NY: State University of New York Press.

Isaacs, H. R. (1975). Basic group identity: The idol of the tribe. In N. Glazer, \& D. P. Moynihan (Eds.), Ethnicity: Theory and experience (pp. 29-52). Cambridge, MA: Harvard University Press.

Joppke, C. (2009). Veil: Mirror of identity. Cambridge: Polity Press. 
Keating, M. (1998). The new regionalism in Western Europe: Territorial restructuring and political change. Cheltenham: Edward Elgar.

Keating, M., \& Loughlin, J. (2013). The political economy of regionalism. Publisher: Routledge.

Keaton, T. D. (2006). Muslim girls and the other France: Race, identity politics, and social exclusion. Bloomington: Indiana University Press.

Kriesi, H., \& Trechsel, A. H. (2008). The politics of Switzerland: Continuity and change in a consensus democracy. Cambridge: Cambridge University Press.

Kukathas, C. (2003). The liberal archipelago. Oxford: Oxford University Press.

Kymlicka, W. (1995). Multicultural citizenship. Oxford: Oxford University Press.

Kymlicka, W. (2001). Politics in the vernacular: Nationalism, multiculturalism, and citizenship. New York: Oxford University Press.

Lemarchand, R. (2004). Exclusion, marginalization, and political mobilization: The road to hell in the Great Lakes. In A. Wimmer, et al. (Eds.), Facing ethnic conflicts: Toward a new realism (pp. 61-77). Oxford: Rowman and Littlefield.

Lin, N. (2008). A network theory of social capital. In D. Castiglione, J. W. v. Deth, \& G. Wolleb (Eds.), The handbook of social capital (pp. 50-69). Oxford: Oxford University Press.

Lipset, S. M., \& Rokkan, S. (Eds.). (1967). Party systems and voter alignments: Cross-national perspective. Publisher: Free Press.

Luhmann, N. (1972). Rechtssoziologie, 2 Bde. Reinbek bei Hamburg: Rowohlt.

Luhmann, N. (1995). Social systems. (J. Bednarz, \& D. Baecker, Trans.). Stanford, CA: Stanford University Press.

Luhmann, N. (2013). Theory of society (vol. 2). (R. Barrett, Trans.). Stanford, CA: Stanford University Press.

Margalit, A., \& Halbertal, M. (2004). Liberalism and the right to culture. Social Research: An International Quarterly, 71(3), 529-548.

McKay, J. (1982). An exploratory synthesis of primordial and mobilizationist approaches to ethnic phenomena. Ethnic and Racial Studies, 5(4), 395-420.

Nagel, J. (1995). American Indian ethnic renewal: Politics and the resurgence of identity. American Sociological Review, 60(6), 947-965.

Nielsen, F. (1985). Toward a theory of ethnic solidarity in modern societies. American Sociological Review, 50(2), $133-149$.

Nussbaum, M. (2000). Women and human development. Cambridge: Cambridge University Press.

Olzak, S. (1992). The dynamics of ethnic competition. Stanford University Press.

Olzak, S. (2006). The global dynamics of racial and ethnic mobilization. Stanford, CA: Stanford University Press.

Ostrom, E. (1990). Governing the commons: The evolution of institutions for collective action. Cambridge: Cambridge University Press.

Park, R. E. (1950). Race and culture. Publisher: Free Press.

Parsons, T. (1951). The social system. Glencoe, IL: Free Press.

Portes, A. (1981). Modes of structural incorporation and present theories of immigration. In M. M. Kritz, et al. (Eds.), Global trends in migration (pp. 279-297). New York, NY: CMS Press.

Putnam, R. D. (1993). Making democracy work: Civil traditions in modern Italy. Princeton, NJ: Princeton University Press.

Putnam, R. D. (2000). Bowling alone: The collapse and revival of American community. New York, MY: Simon and Schuster Paperbacks.

Raz, J. (1994). Ethics in public domain: Essays in the morality of law and politics. Oxford: Clarendon Press.

Roshwald, A. (2006). The endurance of nationalism: Ancient roots and modern dilemmas. Cambridge: Cambridge University Press.

Sanders, J., \& Nee, V. (1987). Limits of ethnic solidarity in the enclave economy. American Sociological Review, 52(6), 745-773.

Scott Jr., G. M. (1990). A resynthesis of the primordial and circumstantial approach to ethnic group solidarity: Towards an Explanatory Model. Ethnic and Racial Studies, 13(2), 147-171.

Sen, A. (1992). Inequality reexamined. Oxford: Oxford University Press.

Sen, A. (2007). Identity and violence: The illusion of destiny. India: Penguin Books.

Shils, E. (1957). Primordial, personal, sacred and civil ties: Some particular observations on the relationships of sociological research and theory. British Journal of Sociology, 8, 130-145.

Silber, L., \& Little, A. (1997). Yugoslavia: Death of a nation. London: Penguin books.

Smith, A. D. (1991). National identity. London: Penguin Books. 
Smith, A. D. (1998). Nationalism and modernism: A critical survey of recent theories of nations and nationalism. London: Routledge.

Taylor, C. (1994). The politics of recognition. In A. Gutmann (Ed.), Multiculturalism: Examining the politics of recognition (pp. 25-73). Publisher: Princeton University Press.

Touraine, A., et al. (1981). Le pays contre l'état: lutes occitanes. Paris: Éditions du Seuil.

Walzer, M. (1983). Spheres of justice: A defense of pluralism and equality. New York, NY: Basic Books.

Webb, A. (2013). Negotiating optimum distinctiveness: Cognitive tendencies toward primordialism among Mapuche youth. Ethnic and Racial Studies, 36(12), 2055-2074.

Wilson, K. L., \& Portes, A. (1980). Immigrant enclaves: An analysis of the labor market experiences of Cubans in Miami. American journal of Sociology, 86(2), 295-319.

Wilson, W. J. (1999). The bridge over the racial divide: Rising inequality and coalition politics. University of California Press. Wilson, W. J. (2012). The truly disadvantaged: The inner city, the underclass, and public policy. University of Chicago Press. 